\title{
Enzalutamide as a second generation antiandrogen for treatment of advanced prostate cancer
}

This article was published in the following Dove Press journal:

Drug Design, Development and Therapy

26 August 2013

Number of times this article has been viewed

\author{
Julius Semenas' \\ Nishtman Dizeyi ${ }^{2}$ \\ Jenny Liao Persson' \\ 'Division of Experimental Cancer \\ Research, Department of Laboratory \\ Medicine, Lund University, Clinical \\ Research Centre, Malmö, Sweden; \\ ${ }^{2}$ Division of Urological Research, \\ Department of Clinical Science, Lund \\ University, Clinical Research Centre, \\ Malmö, Sweden
}

\begin{abstract}
Prostate cancer ( $\mathrm{PCa}$ ) is the most common malignancy, and the third leading cancer-related cause of death among men of the Western world. Upon PCa progression into metastatic disease, androgen deprivation therapy is applied as the first-line treatment, and has been shown to be effective in most patients, leading to a decrease in serum prostate-specific antigen and relief of disease-related symptoms. However, advanced PCa almost inevitably progresses to a castration-resistant state, and is currently regarded as incurable. The large body of evidence indicates that PCa cells remain dependent on androgen receptor (AR) signaling even in an androgen-deprived environment. As such, development of drugs that target AR and AR signaling pathways have become one of the major milestones in treatment of castrationresistant PCa (CRPC). Nevertheless, currently available therapies that target AR signaling are still regarded as palliative and more potent therapies are in great need. Over the past few years, a wide range of novel therapies has entered clinical trial for treatment of CRPC, including androgen synthesis inhibitors (abiraterone acetate), chemotherapeutic agents (docetaxel and cabazitaxel), and immunotherapies (sipuleucel-T). In this context, enzalutamide (previously referred to as MDV3100) is a novel second generation antiandrogen that has been demonstrated to significantly improve survival in men with metastatic CRPC in several clinical trials. In this paper we summarize recently completed and ongoing clinical trials of enzalutamide, and briefly discuss the efficacy of the novel antiandrogen therapy and its limitations for treatment of CRPC.
\end{abstract}

Keywords: castration resistant prostate cancer, drug resistance, clinical trials

\section{Background \\ Prostate cancer $(\mathrm{PCa})$ incidence and mortality rate}

$\mathrm{PCa}$ is the most common malignancy, and the third leading cancer-related cause of death among men of the Western world. According to the most recent available data from World Health Organization (WHO), approximately $75 \%$ of all new PCa cases are diagnosed in developed countries, with world-wide PCa prevalence accounting for approximately 900,000 new cases and 260,000 deaths each year. ${ }^{1}$ While more recent statistical data is yet to be published, PCa in the US alone was estimated to account for approximately 242,000 new cases and 28,000 PCa-related deaths in $2012 .{ }^{2}$ Given that many risk factors, including but not limited to hormone levels, obesity, tobacco, and alcohol consumption, high burden of cancer-related infections or inflammations, sexually transmitted diseases, lack of exercise, and high consumption of animal fat or meat, may predispose to an increase in $\mathrm{PCa}$ incidence, $\mathrm{PCa}$ persists to be the major health burden in the male population of our society. ${ }^{3}$
Correspondence: Jenny Liao Persson Clinical Research Centre (CRC), Malmö University Hospital (SUS), Jan Waldenströms gata 35 , 20502 Malmö, Sweden $\mathrm{Tel}+4640$ 39I 106 Fax +46 40 39I 222

Email jenny_l.persson@med.lu.se 


\section{PCa pathogenesis and androgen deprivation therapy (ADT)}

$\mathrm{PCa}$ is a type of cancer that develops in the prostate gland of the male reproductive system. The development of $\mathrm{PCa}$ has been demonstrated to be driven by androgens (primarily testosterone) and androgen signaling pathways. ${ }^{4}$ Since this discovery was made by two Nobel Prize winners Huggins and Hodges in 1941, the underlying pathogenic mechanisms of PCa have been extensively studied. In 1963, it was demonstrated that most primary PCa tumor cells are initially sensitive to $\mathrm{ADT},{ }^{5}$ which in turn became the first-line treatment for patients with advanced PCa. ${ }^{6,7}$ ADT may be delivered as chemical or surgical castration. While surgical castration includes orchiectomy, ie, the removal of the testicles $(95 \%$ of the body's testosterone source), chemical castration may involve administration of various pharmaceuticals such as luteinizing hormone-releasing hormone (LH-RH) agonist, antiandrogens, or other testosterone biosynthesis-inhibiting drugs. In some cases, a combination therapy of the two may also be applied. ${ }^{8}$ Conclusively, application of ADT may lead to reduction of testosterone biosynthesis and has been demonstrated to result in a decrease in serum prostate-specific antigen (PSA), tumor regression, relief of symptoms, and increased survival of the patients. ${ }^{9-11}$ Approximately $80 \%$ of patients are initially responsive to $\mathrm{ADT} ;{ }^{12}$ however, $\mathrm{ADT}$ only marginally improves the overall survival. ${ }^{13}$ Although considerable progress is being made to improve therapy of $\mathrm{PCa}$, one-third of treated $\mathrm{PCa}$ patients will experience disease recurrence and will progress into castration-resistant $\mathrm{PCa}$ (CRPC). ${ }^{14,15}$ Tumors from PCa patients exhibit genetic complexity such as different epigenetic and genetic alterations that affect multiple genes, and therefore require substantially different treatment regimens. However, most current cancer therapies largely consist of nonspecific cytotoxic agents, and clinical activity is often limited to some subsets of treated patients. ${ }^{16}$ In this context, it is of utmost importance to design and develop anticancer drugs that may specifically target altered pathways in tumor cells.

\section{Treatment of advanced $\mathrm{PCa}$ and treatment failure}

Once a patient is diagnosed with CRPC (earlier referred to as androgen-independent or hormone refractory $\mathrm{PCa}$ ), no currently available therapy may effectively eradicate the disease, and treatment options become scarce. In this context, identification of the major causative factors or signaling pathways which may contribute to the development of CRPC is crucial for designing novel treatment strategies.
Numerous studies have shown that androgen receptor (AR)-mediated signaling plays an important role in the development of CRPC, which may render PCa cells to become resistant to treatment. In addition, the presence of a subpopulation of cancer cells within a tumor that remain to be dependent on AR-mediated signaling during further tumor growth and disease progression has been reported. ${ }^{17,18}$ In this context, AR overexpression, AR amplification, mutationinduced changes, and intratumoral testosterone synthesis have been recognized and hypothesized to be driving PCa progression in the presence of even minimal levels of androgens. ${ }^{19-23}$ Moreover, alternative activation of AR through crosstalk with other cellular signaling pathways in tumor growth and CRPC progression has been reported. ${ }^{24-27}$ Conclusively, the available data provide robust evidence that $\mathrm{AR}$ and its cofactors in the CRPC setting are important therapeutic targets. ${ }^{28-30}$

As mentioned above, CRPC until recently was regarded as androgen-independent $\mathrm{PCa} .{ }^{31} \mathrm{As}$ such, patients that have been diagnosed with CRPC were often prescribed standard taxane-based chemotherapeutic drugs, such as docetaxel and cabazitaxel in combination with prednisone. ${ }^{32-34}$ However, these therapies have been reported to offer a mere 2-month survival benefit ${ }^{35}$ and often lead to development of drug resistance to taxane-based chemotherapy. ${ }^{36-39}$ The failure of therapy in PCa patients may reflect the complexity of PCa. It is known that there is enormous genomic heterogeneity in various human cancers, and the role of the genomic heterogeneity in the response to therapy is still poorly understood. ${ }^{16}$ Taxane-based chemotherapeutic drugs such as docetaxel belong to cytotoxic agents, which do not target specific signaling pathways that actually drive cancer cell progression, and the use of such therapies often leads to further cancer cell mutations and acquisition of multidrug resistance.

\section{Novel classes of drugs that target AR signaling}

There is an urgent need to design and develop novel drugs that may selectively target major signaling pathways that contribute to CRPC. Since AR-associated pathways are responsible for cancer cell growth and survival, and even enable the cancer cells to grow in the presence of minimal androgen levels, ${ }^{40,41} \mathrm{AR}$ signaling is an ideal target for designing and developing such drugs. In this regard, a multitude of first generation antiandrogens such as flutamide (Eulexin ${ }^{\circledR}$, Merck and Co, Inc, Whitehouse Station, NJ, USA), nilutamide (Nilandron ${ }^{\circledR}$, Sanofi SA, Paris, France), cyproterone acetate $\left(\right.$ Cyprostat $^{\circledR}$, Bayer AG, Leverkusen, Germany; Androcur $^{\circledR}$, Bayer AG), and bicalutamide $\left(\right.$ Casodex $^{\circledR}$, 
IPR Pharmaceuticals, Inc, Canóvanas, Puerto Rico) have failed to demonstrate substantial effects in CRPC patients. Moreover, AR-agonizing effects of these drugs were also reported. ${ }^{42,43}$ It is not until recently that novel classes of drugs that effectively target AR signaling in advanced PCa have been developed; these are currently undergoing clinical trials. Enzalutamide is one such drug, and is the focus in this review article. We will specifically assess the advantages and disadvantages of this drug by detailed evaluation of data obtained from several past and currently ongoing clinical trials.

\section{Discovery and development of enzalutamide}

Enzalutamide, formerly known as MDV3100 (Figure 1), is a second-generation antiandrogen licensed by Medivation (San Francisco, CA, USA), which has been specifically designed to bind and inhibit AR, ${ }^{44}$ with no reported agonistic effects. ${ }^{45}$ Enzalutamide was selected from approximately 170 smallmolecule candidates tested in PCa cancer cell lines and animal models, and that had significant inhibitory effect on tumor growth and progression in bicalutamide-resistant $\mathrm{PCa}$ animal models (Figure 1). More importantly, in the study, enzalutamide demonstrated tumor growth inhibition, and lowered the level of AR overexpression in tumor cells. ${ }^{28}$ Thus, enzalutamide was selected for clinical trials and was approved by the US Food and Drug Administration on August 31, 2012, for the treatment of patients with metastatic CRPC who have previously received docetaxel-based chemotherapy. ${ }^{46}$ The underlying mechanisms of the demonstrated antitumor effects have been elucidated, and it is now established that enzalutamide exerts its antitumor effect by inhibiting several steps in the AR signaling pathway; it competitively inhibits androgen and AR binding to androgens, as well as inhibits AR nuclear translocation and interaction with DNA. ${ }^{47}$ The well defined mode of action of enzalutamide and its selective targets made it possible to accelerate the progress of drug development using enzalutamide as mono- or combination therapy.

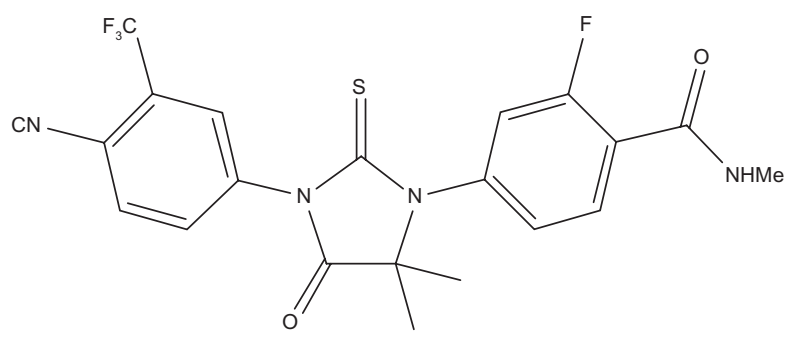

Figure I Molecular structure of enzalutamide.
Although the data from the clinical trials of enzalutamide for treatment of advanced PCa are limited, we have collected all available information from reported meeting abstracts, published studies, and from the ClinicalTrials.gov registry and result database. The first clinical trial, NCT00510718 was published in 2010 , by Scher and colleagues. ${ }^{48}$ The study enrolled a total of 140 patients with progressive CRPC, with data available in a publication. ${ }^{49}$ Another Phase I-II clinical trial, NCT01565928 was also conducted by Scher and colleagues. ${ }^{48}$ However, only a meeting abstract addressing this clinical trial was available. ${ }^{50}$ To reflect on the further development of enzalutamide in clinical trials, we used information from ClinicalTrials.gov registry and result database. According to ClinicalTrials.gov, there were 13 registered clinical trials assessing enzalutamide in the CRPC setting, with one study being withdrawn prior to enrolment. ${ }^{51}$ An overview of the clinical trials, their respective stage, status, and primary completion dates are presented in Table 1.

\section{Clinical trials of enzalutamide Clinical trial design and settings}

As mentioned above, the data of the various enzalutamide studies is very limited. As such, we will focus our evaluations on the few published or available sources. Among the two studies that were completed (NCT00510718 and NCT01565928), two additional open-label efficacy and safety studies have recently reached the primary completion date (NCT01091103 and NCT01302041), ${ }^{48}$ and other studies are still ongoing (NCT01547299, NCT01650194, NCT01664923, and NCT01288911) ${ }^{48}$ (Table 1). Because enzalutamide is aimed to treat advanced $\mathrm{PCa}$, in particular CRPC, it is important to look into several criteria that were used for patient selection, drug efficacy, and drug toxicity. One Phase I clinical trial enrolled a total of 140 patients with progressive CRPC who were divided into dose-escalation cohorts of three to six individuals. Starting treatment dose was $30 \mathrm{mg}$ of enzalutamide, which was administered orally every day. The daily doses included $30 \mathrm{mg}(\mathrm{n}=3), 60 \mathrm{mg}$ $(\mathrm{n}=27), 150 \mathrm{mg}(\mathrm{n}=28), 240 \mathrm{mg}(\mathrm{n}=29), 360 \mathrm{mg}(\mathrm{n}=28)$, $480(\mathrm{n}=22)$, and $600 \mathrm{mg}(\mathrm{n}=3)$ (NCT00510718). In parallel, another Phase I-II clinical trial had similar numbers of patients, with a total of 120 patients with CRPC, 73 of whom were treated with 60, 150, and $240 \mathrm{mg}$ /day of enzalutamide, followed for 24 weeks (NCT01565928). These two clinical trials were designed to treat CRPC patients with enzalutamide using the same regimens. In addition, most of the registered Phase I and II clinical trials listed in Table 1 enrolled patients with CRPC with the aim to evaluate 
Table I Summary of current clinical trials of enzalutamide against PCa

\begin{tabular}{|c|c|c|c|c|c|}
\hline Study ID & Phase & Individuals enrolled (n) & Condition & Status & Primary completion date \\
\hline NCT0I09II03 & II & 60 & Metastatic CRPC & Active, not recruiting & September, 201I \\
\hline NCT009743II & III & 1,199 & CRPC & Active, not recruiting & November, 201I \\
\hline NCT0I 284920 & $I-I I$ & 46 & $\begin{array}{l}\text { Prostate neoplasm/ } \\
\text { PCa/CRPC }\end{array}$ & Recruiting & December, 2012 \\
\hline NCT0I30204I & II & 60 & $\mathrm{PCa}$ & Active, not recruiting & July, 2012 \\
\hline NCT005I07I8 & 1 & 100 & $\mathrm{PCa} / \mathrm{CRPC}$ & Active, not recruiting & July, 2012 \\
\hline NCT0I547299 & II & 50 & $\mathrm{PCa}$ & Recruiting & June, 2013 \\
\hline NCT0I650I94 & II & 60 & Metastatic CRPC & Recruiting & June, 2013 \\
\hline NCT0I664923 & II & 400 & $\mathrm{PCa}$ & Recruiting & July, 2013 \\
\hline NCT0I2889II & II & 370 & Prostate neoplasm & Recruiting & July, 2013 \\
\hline NCT0I565928 & I & 18 & $\mathrm{PCa}$ & Active, not recruiting & March, 2014 \\
\hline NCT0 I 2 I 299I & III & 1,680 & $\mathrm{PCa}$ & Recruiting & September, 2014 \\
\hline NCT0I6634I5 & II & 0 & Metastatic CRPC & Withdrawn & October, 2014 \\
\hline NCT0I534052 & II & 14 & CRPC & Enrolling by invitation & December, 2022 \\
\hline
\end{tabular}

Abbreviations: CRPC, castration-resistant prostate cancer; $\mathrm{PCa}$, prostate cancer.

the efficacy of enzalutamide on CRPC patients as a single agent. Of particular interest, two Phase II clinical trials, NCT01091103 and NCT01650194, have enrolled patients with metastatic CRPC, enrolling a total of 60 patients each. According to the ClinicalTrials.gov database, NCT01091103 was completed September, 2011, and NCT01650194 will be completed June, 2013. The result from these trials will be of great importance for further validation and clinical use of enzalutamide for treatment of metastatic PCa.

To ensure that a drug candidate can be developed into a drug for treatment of patients in the clinics, it is of importance to evaluate the safety and tolerability of the drug. In the NCT00510718 clinical trial, the maximum tolerated dose of enzalutamide was assessed, the patients were examined at monthly intervals, and toxicity was graded in accordance with National Cancer Institute Common Terminology Criteria for Adverse Events, version 3.0. Published results revealed that the maximum tolerated dose of $>28$ days sustained treatment was $240 \mathrm{mg}$, with fatigue being the most common adverse event (in 11\%). Other adverse events including anemia (in 3\%), arthritis (in 2\%), asthenia (in 2\%), and even seizures (in $2 \%$, only in the $360 \mathrm{mg}, 480 \mathrm{mg}$, and $600 \mathrm{mg}$ treatment groups) were noted in all dosing groups. Conclusively, the data suggested that enzalutamide was generally well tolerated, and indicated minimal toxicity to PCa patients. ${ }^{49}$

The criteria used for evaluating the efficacy of enzalutamide in the NCT00510718 clinical trial was selected based on the guidelines from the Prostate Cancer Clinical Trials Working Group 2 criteria, with positive antitumor effect defined as $\geq 50 \%$ serum PSA decrease. Additional criteria included soft-tissue disease evaluation by the Response Evaluation Criteria in Solid Tumors, 16 beta(18F)-fluoro-5 alpha-dihydrotestosterone and 2-(18F)-fluoro-2-deoxy-Dglucose positron emission tomography (PET) and computer tomography imaging, and circulating tumor cell (CTC) counts determined by CellSearch assay. ${ }^{49}$ Primary and secondary outcome measurements using overall survival and biochemical recurrence based on PSA levels were applied to evaluate the long-term effect of enzalutamide. At the same time, Phase I-II clinical trial NCT01565928 used similar criteria to define the efficacy of enzalutamide. ${ }^{50}$

It is of importance to note that Phase III clinical trial NCT00974311 enrolled 1,199 CRPC patients who were previously treated with other chemotherapeutics, such as docetaxel. ${ }^{48}$ The patients were randomly assigned to treatment versus placebo group in a 2:1 ratio and received daily $160 \mathrm{mg}$ oral dose of enzalutamide $(n=800)$ or placebo $(n=399)$. In this context, the criterion for measurement of efficacy was the patient outcome, including overall survival as the primary outcome measurement. The secondary outcome measurement was radiographic progression-free survival, time to first skeletal-related event, functional assessment of cancer therapy, time to biochemical reoccurrence defined by $\geq 25 \%$ increase, and $\geq 2 \mathrm{ng} / \mathrm{mL}$ absolute increase in PSA, percentage of patients with pain palliation, percentage of patients with PSA response, percentage of patients with soft-tissue objective response, European Quality of Life Five-Domains, and conversion rate of circulating tumor cells (NCT00974311).

\section{Clinical trial outcomes}

The results from NCT00510718 and NCT01565928 clinical trials indicate that enzalutamide may be an effective drug for treatment of CRPC, with good safety profiles and well known mode of action. Enzalutamide has demonstrated significantly 
superior effects in patients without previous treatment with other chemotherapeutic drugs compared with patients who received previous treatment. Patients who were treated with enzalutamide had significantly higher overall survival and progression-free survival, as measured by serum PSA levels or radiographic imaging (Figure 2). ${ }^{49}$ As such, the study demonstrated that enzalutamide has encouraging antitumor activity in CRPC patients.

Similar promising results were also obtained from Phase I clinical trial NCT01565928. PSA decline of 50\% or more was observed in 22 out of 42 naïve (55\%), and 13 out of 31

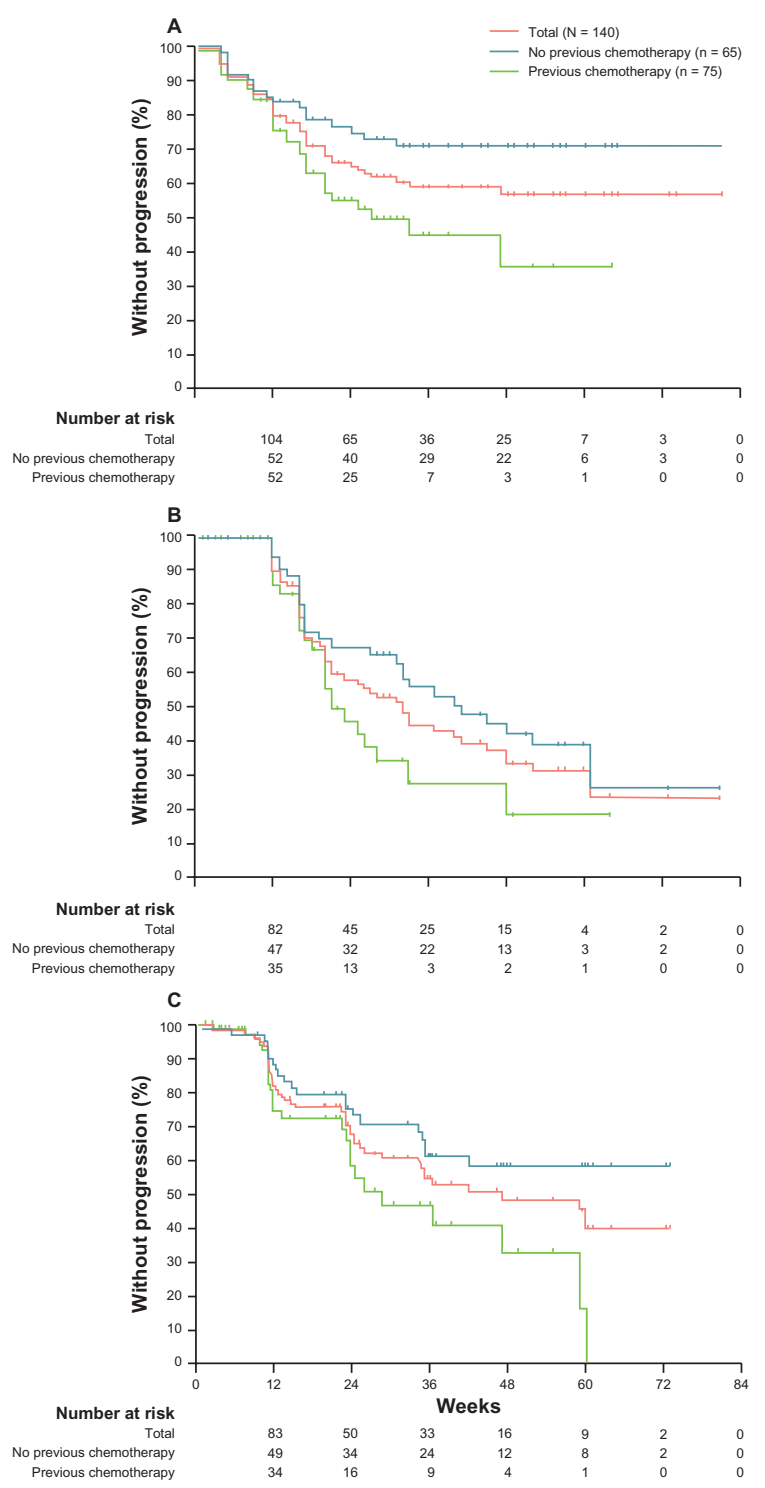

Figure 2 Kaplan-Meier estimates of primary and secondary outcome measures in Phase I-II clinical trial of enzalutamide (ClinicalTrials.gov identifier: NCT005I07 I8). (A) PSA progression defined as $\geq 25 \%$ increase in PSA from baseline. (B) PSA progression defined by Prostate Cancer Working Group criteria as $\geq 25 \%$ increase from nadir. (C) Progression-free survival defined by radiological imaging in chemotherapy-naïve and chemotherapy-treated patients. Reprinted from Scher HI, Beer TM, Higano CS, et al, Antitumour activity of MDV 3100 in castration-resistant prostate cancer: a phase I-2 study. Lancet. 375:1437-1446. Copyright 2010, with permission from Elsevier. ${ }^{49}$ Abbreviation: PSA, prostate-specific antigen.
$(42 \%)$ post-chemo patients. This study has demonstrated that enzalutamide therapy promotes antitumor activity, which was also well supported by PSA decline, CTC changes, and PET imaging findings. Moreover, the data indicated a doseresponsive trend, and further suggested enzalutamide as a promising candidate for treatment of CRPC. ${ }^{50}$

In addition, according to the published results from Phase III clinical trial NCT00974311, enzalutamide showed the overall survival benefit of 5.2 months; 18.4 months (95\% confidence interval [CI], 17.3 to not-yet-reached time point) in enzalutamide group versus 13.6 months (95\% CI, 11.3-15.8) in control group. Moreover, superiority of enzalutamide in treatment versus control group in secondary outcome measures was also well demonstrated, and included reduction in serum PSA (54\% versus 2\%), soft-tissue response rate ( $29 \%$ versus $4 \%, P<0.001$ ), the quality-of-life response

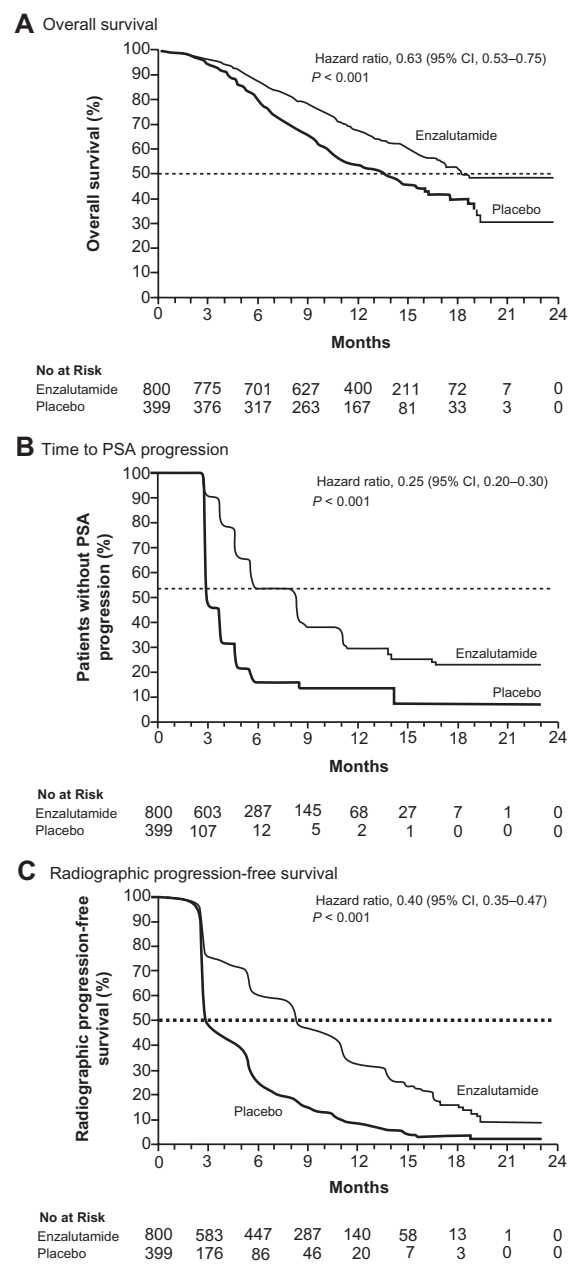

Figure 3 Kaplan-Meier estimates of primary and secondary outcome measures in Phase III clinical trial of enzalutamide (ClinicalTrials.gov identifier: NCT009743 I I). (A) Overall survival. (B) Progression-free survival defined by prostate-specific antigen progression. (C) Progression-free survival defined by radiological imaging. From N Engl J Med, Scher HI, Fizazi K, Saad F, et al. Increased survival with enzalutamide in prostate cancer after chemotherapy. 367; I 187-1 197. Copyright (C 20I2 Massachusetts Medical Society. Reprinted with permission from Massachusetts Medical Society. ${ }^{52}$ Abbreviations: $\mathrm{Cl}$, confidence interval; PSA, prostate-specific antigen. 
rate (43\% versus $18 \%, P<0.001)$, time to PSA progression (8.3 versus 3.0 months, $P<0.001$ ), and time to first skeletalrelated event (16.7 versus 13.3 months, $P<0.001) .{ }^{52}$ Conclusively, the study has demonstrated that enzalutamide significantly prolonged the survival of patients with metastatic CRPC after docetaxel-based chemotherapy.

\section{Conclusion and final remarks}

Recently, a rapid increase in the number of effective systemic therapies for men with metastatic CRPC has significantly changed the treatment paradigm and expanded the treatment options for the advanced stages of the disease. ${ }^{34,53,55}$ Although enzalutamide demonstrated highly promising effects, it appears that there is still a fraction of patients who fail to respond to such therapy (Figures 2 and 3). Moreover, the failure to respond to enzalutamide therapy is more prominent in patient subgroups that have been previously treated with other chemotherapeutic drugs (Figure 2). Tumors from patients who did not respond to enzalutamide may have developed multiple drug resistance, in which additional alterations in AR signaling may have occurred in tumor cells. Indeed, such resistance may be in part explained by recent findings reported by Li and colleagues, who have shown that specific AR splice variants may mediate enzalutamide resistance in PCa cell lines. ${ }^{54}$ These findings therefore indicate that identification of a PCa patient group that may benefit from treatment of enzalutamide is a crucial step in improving enzalutamide efficacy, and may assist in directing future clinical trials.

The available data suggest that enzalutamide is a potent antiandrogen drug that is substantially superior to its firstgeneration functional analogs. Moreover, the antagonistic potential of enzalutamide versus other antiandrogens such as bicalutamide is also well contrasted. In this context, the efficacy of enzalutamide has been clearly reflected in numerous clinical trials, and indeed has demonstrated very promising results with minimal side effects. Conclusively, clinical trials of enzalutamide indicate this novel second-generation antiandrogen as the new steppingstone for future advanced PCa therapies, and provide further proof that AR-signaling remains to play the pivotal role in progression of advanced PCa. Moreover, identification of a PCa patient group that may benefit from treatment of enzalutamide is a crucial step in improving enzalutamide efficacy, and may direct the design of upcoming clinical trials. As such, a deeper understanding of molecular and cellular mechanisms underlying PCa responses to enzalutamide is required.

\section{Acknowledgments}

The Swedish Cancer Society, the Swedish National Research Council, MAS Cancer Foundation, Gunna Nilsson Cancer Foundation and Crafoord Foundation, Government Health Grant and MAS Foundation (to JLP).

\section{Disclosure}

The authors report no conflicts of interest in this work.

\section{References}

1. GLOBOCAN v1.2 Cancer Incidence and Mortality Worldwide: IARC CancerBase No. 10. 2008.

2. Siegel R, Naishadham D, Jemal A. Cancer statistics, 2012. CA Cancer J Clin. 2012;62(1):10-29.

3. Semenas J, Allegrucci C, Boorjian SA, Mongan NP, Persson JL. Overcoming drug resistance and treating advanced prostate cancer. Curr Drug Targets. 2012;13(10):1308-1323.

4. Huggins C, Hodges CV. Studies on prostatic cancer. I. The effect of castration, of estrogen and of androgen injection on serum phosphatases in metastatic carcinoma of the prostate. 1941. J Urol. 2002;167(2 Pt 2): 948-951; discussion 952.

5. Huggins C. The hormone-dependent cancers. JAMA. 1963;186: 481-483.

6. Perlmutter MA, Lepor H. Androgen deprivation therapy in the treatment of advanced prostate cancer. Rev Urol. 2007;9 Suppl 1:S3-S8.

7. Harris WP, Mostaghel EA, Nelson PS, Montgomery B. Androgen deprivation therapy: progress in understanding mechanisms of resistance and optimizing androgen depletion. Nat Clin Pract Urol. 2009;6(2):76-85.

8. National Cancer Institute [homepage on the Internet]. Prostate cancer. National Institutes of Health; 2012. Available from: http://cancer.gov/ cancertopics/wyntk/prostate. Accessed June 5, 2013.

9. Crawford ED, Eisenberger MA, McLeod DG, et al. A controlled trial of leuprolide with and without flutamide in prostatic carcinoma. $N$ Engl J Med. 1989;321(7):419-424.

10. Eisenberger MA, Blumenstein BA, Crawford ED, et al. Bilateral orchiectomy with or without flutamide for metastatic prostate cancer. N Engl J Med. 1998;339(15):1036-1042.

11. Crawford ED. Combined androgen blockade. Urology. 1989; 34(4 Suppl):22-26; discussion 46-56.

12. The Leuprolide Study Group. Leuprolide versus diethylstilbestrol for metastatic prostate cancer. $N$ Engl J Med. 1984;311(20):1281-1286.

13. Walsh PC. Immediate versus deferred treatment for advanced prostatic cancer: initial results of the Medical Research Council trial. The Medical Research Council Prostate Cancer Working Party Investigators Group. J Urol. 1997;158(4):1623-1624.

14. Messing EM, Manola J, Sarosdy M, Wilding G, Crawford ED, Trump D. Immediate hormonal therapy compared with observation after radical prostatectomy and pelvic lymphadenectomy in men with node-positive prostate cancer. $N$ Engl J Med. 1999;341(24):1781-1788.

15. Maximum androgen blockade in advanced prostate cancer: an overview of the randomised trials. Prostate Cancer Trialists' Collaborative Group. Lancet. 2000;355(9214):1491-1498.

16. Sharma SV, Haber DA, Settleman J. Cell line-based platforms to evaluate the therapeutic efficacy of candidate anticancer agents. Nat Rev Cancer. 2010;10(4):241-253.

17. Holzbeierlein J, Lal P, LaTulippe E, et al. Gene expression analysis of human prostate carcinoma during hormonal therapy identifies androgenresponsive genes and mechanisms of therapy resistance. Am J Pathol. 2004;164(1):217-227.

18. Shah RB, Mehra R, Chinnaiyan AM, et al. Androgen-independent prostate cancer is a heterogeneous group of diseases: lessons from a rapid autopsy program. Cancer Res. 2004;64(24):9209-9216. 
19. Tamura K, Furihata M, Tsunoda T, et al. Molecular features of hormonerefractory prostate cancer cells by genome-wide gene expression profiles. Cancer Res. 2007;67(11):5117-5125.

20. Koivisto P, Kononen J, Palmberg C, et al. Androgen receptor gene amplification: a possible molecular mechanism for androgen deprivation therapy failure in prostate cancer. Cancer Res. 1997;57(2):314-319.

21. Chen CD, Welsbie DS, Tran C, et al. Molecular determinants of resistance to antiandrogen therapy. Nat Med. 2004;10(1):33-39.

22. Stanbrough M, Bubley GJ, Ross K, et al. Increased expression of genes converting adrenal androgens to testosterone in androgen-independent prostate cancer. Cancer Res. 2006;66(5):2815-2825.

23. Montgomery RB, Mostaghel EA, Vessella R, et al. Maintenance of intratumoral androgens in metastatic prostate cancer: a mechanism for castration-resistant tumor growth. Cancer Res. 2008;68(11): 4447-4454.

24. Seruga B, Ocana A, Tannock IF. Drug resistance in metastatic castrationresistant prostate cancer. Nat Rev Clin Oncol. 2011;8(1):12-23.

25. Yeh S, Miyamoto H, Shima H, Chang C. From estrogen to androgen receptor: a new pathway for sex hormones in prostate. Proc Natl Acad Sci US A. 1998;95(10):5527-5532.

26. Yeh S, Kang HY, Miyamoto H, et al. Differential induction of androgen receptor transactivation by different androgen receptor coactivators in human prostate cancer DU145 cells. Endocrine. 1999;11(2): 195-202.

27. Gregory CW, He B, Johnson RT, et al. A mechanism for androgen receptor-mediated prostate cancer recurrence after androgen deprivation therapy. Cancer Res. 2001;61(11):4315-4319.

28. Tran C, Ouk S, Clegg NJ, et al. Development of a second-generation antiandrogen for treatment of advanced prostate cancer. Science. 2009;324(5928):787-790.

29. Wang Q, Li W, Zhang Y, et al. Androgen receptor regulates a distinct transcription program in androgen-independent prostate cancer. Cell. 2009;138(2):245-256.

30. Clegg NJ, Wongvipat J, Joseph JD, et al. ARN-509: a novel antiandrogen for prostate cancer treatment. Cancer Res. 2012;72(6):1494-1503.

31. Scher HI, Sawyers CL. Biology of progressive, castration-resistant prostate cancer: directed therapies targeting the androgen-receptor signaling axis. J Clin Oncol. 2005;23(32):8253-8261.

32. Petrylak DP, Tangen CM, Hussain MH, et al. Docetaxel and estramustine compared with mitoxantrone and prednisone for advanced refractory prostate cancer. $N$ Engl J Med. 2004;351(15):1513-1520.

33. Tannock IF, de Wit R, Berry WR, et al. Docetaxel plus prednisone or mitoxantrone plus prednisone for advanced prostate cancer. $N$ Engl J Med. 2004;351(15):1502-1512.

34. de Bono JS, Oudard S, Ozguroglu M, et al. Prednisone plus cabazitaxel or mitoxantrone for metastatic castration-resistant prostate cancer progressing after docetaxel treatment: a randomised open-label trial. Lancet. 2010;376(9747):1147-1154.

35. Berthold DR, Pond GR, Soban F, de Wit R, Eisenberger M, Tannock IF. Docetaxel plus prednisone or mitoxantrone plus prednisone for advanced prostate cancer: updated survival in the TAX 327 study. J Clin Oncol. 2008;26(2):242-245.

36. Darshan MS, Loftus MS, Thadani-Mulero M, et al. Taxane-induced blockade to nuclear accumulation of the androgen receptor predicts clinical responses in metastatic prostate cancer. Cancer Res. 2011; 71(18):6019-6029.

37. Gottesman MM, Fojo T, Bates SE. Multidrug resistance in cancer: role of ATP-dependent transporters. Nat Rev Cancer. 2002;2(1):48-58.
38. Berrieman HK, Lind MJ, Cawkwell L. Do beta-tubulin mutations have a role in resistance to chemotherapy? Lancet Oncol. 2004;5(3): $158-164$.

39. Bhalla KN. Microtubule-targeted anticancer agents and apoptosis. Oncogene. 2003;22(56):9075-9086.

40. Metzger E, Wissmann M, Yin N, et al. LSD1 demethylates repressive histone marks to promote androgen-receptor-dependent transcription. Nature. 2005;437(7057):436-439.

41. Kahl P, Gullotti L, Heukamp LC, et al. Androgen receptor coactivators lysine-specific histone demethylase 1 and four and a half LIM domain protein 2 predict risk of prostate cancer recurrence. Cancer Res. 2006;66(23):11341-11347.

42. Culig Z, Hoffmann J, Erdel M, et al. Switch from antagonist to agonist of the androgen receptor bicalutamide is associated with prostate tumour progression in a new model system. Br J Cancer. 1999;81(2): 242-251.

43. Nguyen TV, Yao M, Pike CJ. Flutamide and cyproterone acetate exert agonist effects: induction of androgen receptor-dependent neuroprotection. Endocrinology. 2007;148(6):2936-2943.

44. Medivation. Medivation's MDV3100 shown to be effective in a preclinical model of hormone-refractory prostate cancer [press release]. San Francisco, CA: Medivation; 2007 [February 26]. Available from: http://investors.medivation.com/releasedetail.cfm?ReleaseID=231214. Accessed June 5, 2013.

45. Massard C, Fizazi K. Targeting continued androgen receptor signaling in prostate cancer. Clin Cancer Res. 2011;17(12):3876-3883.

46. US Food and Drug Administration. Enzalutamide (XTANDI capsules). Silver Spring, MD: US Food and Drug Administration; 2012. Available from: http://www.fda.gov/Drugs/InformationOnDrugs/ApprovedDrugs/ ucm317997.htm. Accessed June 5, 2013.

47. XTANDI [prescribing information]. Northbrook, IL: Astellas Pharma US, Inc; 2012.

48. ClinicalTrials.gov. Available from: http://www.clinicaltrials.gov/ct2/ home. Accessed 1 July, 2013.

49. Scher HI, Beer TM, Higano CS, et al. Antitumour activity of MDV3100 in castration-resistant prostate cancer: a phase 1-2 study. Lancet. 2010;375(9724):1437-1446.

50. Scher HI, Beer TM, Higano CS, et al. Phase I-II study of MDV3100 in castration-resistant prostate cancer (CRPC). J Clin Oncol. 2009;27: abstract 151 .

51. ClinicalTrials. Current clinical trials for MDV3100. 2012; http://www. clinicaltrials.gov/ct2/results?term=MDV3100\&recr=\&rslt=\&type=Intr \& cond $=\&$ intr $=\&$ outc $=\&$ spons $=$ Astellas $\&$ lead $=\& \mathrm{id}=\&$ state $1=\&$ cntry 1 $=\&$ state $2=\&$ cntry $2=\&$ state $3=\&$ cntry $3=\&$ locn $=\&$ gndr $=\&$ phase $=0 \&$ pha $\mathrm{se}=1 \&$ phase $=2 \&$ phase $=3 \& \mathrm{rcv} \_\mathrm{s}=\& \mathrm{rcv} \_\mathrm{e}=\&$ lup_s$=\& l u p \_\mathrm{e}=$. Accessed March 14, 2012.

52. Scher HI, Fizazi K, Saad F, et al. Increased survival with enzalutamide in prostate cancer after chemotherapy. $N$ Engl J Med. 2012;367(13): 1187-1197.

53. de Bono JS, Logothetis CJ, Molina A, et al. Abiraterone and increased survival in metastatic prostate cancer. $N$ Engl J Med. 2011;364(21): 1995-2005.

54. LiY, Chan SC, Brand LJ, Hwang TH, Silverstein KA, Dehm SM. Androgen receptor splice variants mediate enzalutamide resistance in castrationresistant prostate cancer cell lines. Cancer Res. 2013;73(2): 483-489.

55. Kantoff PW, Higano CS, Shore ND, et al. Sipuleucel-T immunotherapy for castration-resistant prostate cancer. $N$ Engl J Med. 2010;363(5): $411-422$.

\section{Publish your work in this journal}

Drug Design, Development and Therapy is an international, peerreviewed open-access journal that spans the spectrum of drug design and development through to clinical applications. Clinical outcomes, patient safety, and programs for the development and effective, safe, and sustained use of medicines are a feature of the journal, which

has also been accepted for indexing on PubMed Central. The manuscript management system is completely online and includes a very quick and fair peer-review system, which is all easy to use. Visit http://www.dovepress.com/testimonials.php to read real quotes from published authors. 